\title{
Early Experience with Comaneci, a Newly FDA-Approved Controllable Assist Device for Wide-Necked Intracranial Aneurysm Coiling
}

\author{
M. Asif Taqia Eytan Raz ${ }^{b}$ Anastasia Vechera ${ }^{a}$ Maksim Shapiro ${ }^{b}$ Rishi Guptac \\ Joseph Haynes ${ }^{d}$ Philipp Taussky ${ }^{\mathrm{e}}$ Ramesh Grandhi ${ }^{\mathrm{e}}$ Howard A. Riina $^{\mathrm{f}}$ \\ Peter Kim Nelson $^{b} \quad$ Erez Nossek $^{f}$ \\ avascular Neurology of Southern California, Thousand Oaks, CA, USA; ${ }^{b}$ Department of Radiology, Section of \\ Neurointerventional Radiology, NYU Langone Health, New York, NY, USA; 'Department of Neurosurgery, \\ Wellstar Medical Group, Kennestone Hospital, Atlanta, GA, USA; ${ }^{d}$ School of Medicine and Dentistry, University of \\ Rochester, Rochester, NY, USA; ${ }^{\text {DDepartment }}$ of Neurosurgery, Clinical Neurosciences Center, University of Utah, \\ Salt Lake City, UT, USA; fDepartment of Neurosurgery, NYU Langone Health, New York, NY, USA
}

\section{Keywords}

Aneurysm · Coil embolization · Comaneci · Bridging device

\begin{abstract}
Background: Comaneci (Rapid Medical) is a compliant, adjustable mesh that provides temporary scaffolding during coiling of wide-necked intracranial aneurysms (WNAs) that preserves antegrade flow. We report our early multi-institutional experience with the Comaneci device in the USA. Method: We reviewed all patients with WNAs that were treated using the Comaneci device for coil remodeling of ruptured and unruptured aneurysms at 4 institutions between July 2019 and May 2020. Clinical characteristics, angiographic variables, and endovascular results were assessed. Results: A total of 26 patients were included (18 women). The mean age was 62.7 years (range $44-81$ ). Fifteen patients presented with ruptured aneurysms and 11 with unruptured aneurysms. The mean aneurysm neck width was $3.91 \mathrm{~mm}$ (range 1.9-6.5) with a mean dome-to-neck ratio of 1.57 (range 0.59-3.39). The mean maximum width was 5.80
\end{abstract}

karger@karger.com www.karger.com/ced

Karger $\frac{1}{\%}$
(C) 2021 The Author(s)

Published by S. Karger AG, Basel

This is an Open Access article licensed under the Creative Commons Attribution-NonCommercial-4.0 International License (CC BY-NC) (http://www.karger.com/Services/OpenAccessLicense), applicable to the online version of the article only. Usage and distribution for commercial purposes requires written permission. $\mathrm{mm}$ (range 3.0-9.9) and the mean maximum height was 5.61 $\mathrm{mm}$ (range 2.0-11.8). Successful aneurysm occlusion was achieved in 25 of 26 patients. Complete occlusion was achieved in 16 patients, near-complete occlusion was observed in 9 patients, and 1 patient demonstrated residual filling. The mean time of device exposure was 24 min (range 8-76). No vasospasm was observed at the device location. Clot formation on the device was noted in 2 separate cases, but there were no clinical sequelae. There was 1 intraprocedural complication in a case that involved the simultaneous use of 2 Comaneci devices. Conclusions: Our initial experience shows that the Comaneci device is a promising and reliable tool that can safely support coil remodeling of WNAs.

(C) 2021 The Author(s)

Published by S. Karger AG, Basel

\section{Background and Introduction}

Wide-necked intracranial aneurysms (WNAs) are among the most difficult vascular lesions to treat. Historically, these aneurysms were mainly treated with mi- 

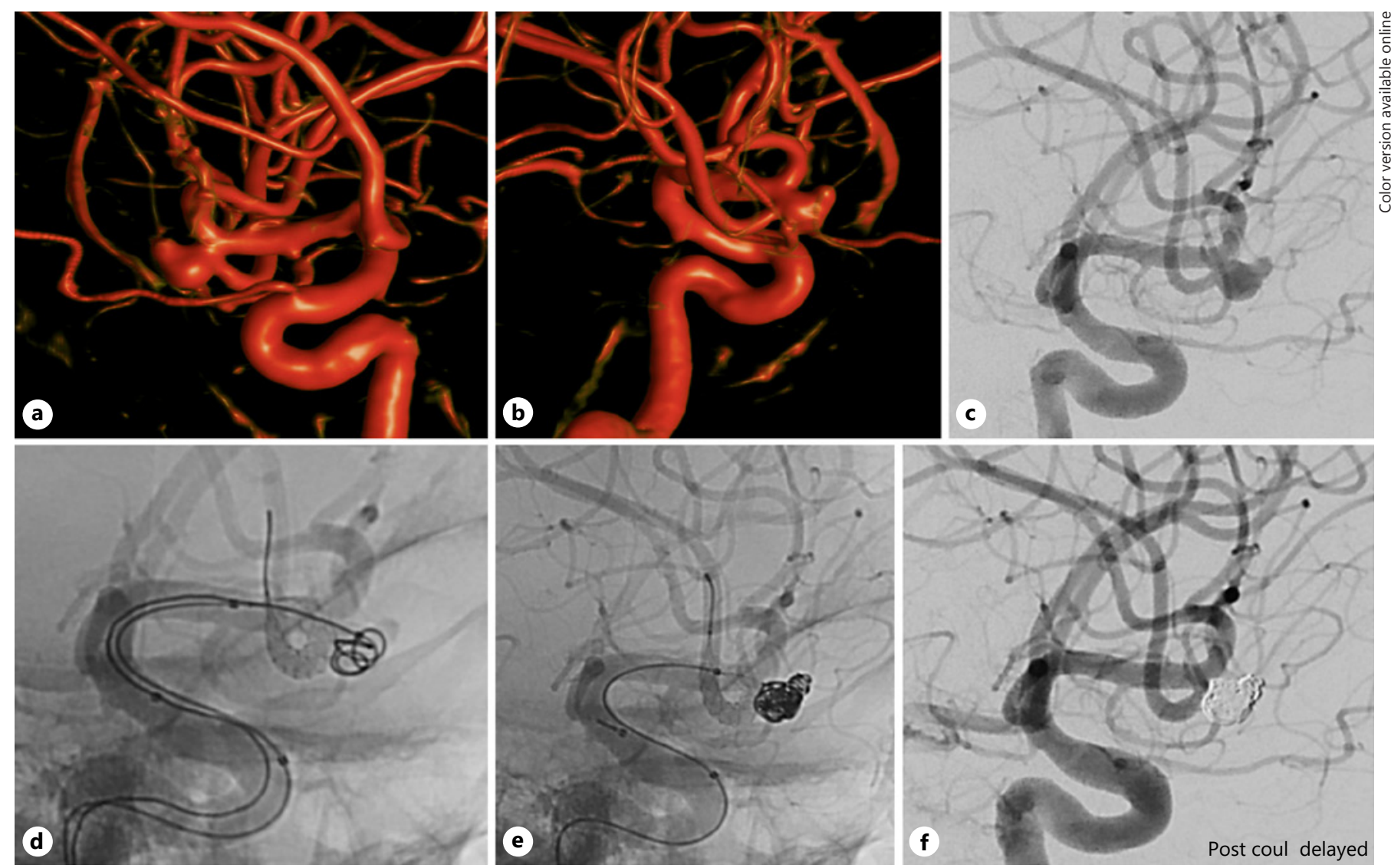

Fig. 1. Unruptured MCA aneurysm. Wide neck involving mainly the inferior division. a, b 3D reconstruction of the right ICA. c Lateral oblique 2D DSA demonstrating the MCA aneurysm with a daughter sac pointing superiorly. d, e Unsubtracted angiograms showing inflated Comaneci while the first framing coil is pushed and after the last coil is deployed into the aneurysm. $\mathbf{f}$ DSA final result demonstrating complete occlusion of the aneurysm. MCA, middle cerebral artery; ICA, internal carotid artery.

crosurgical clipping, whereas those with narrow necks were considered more favorable for endovascular coiling [1]. The randomized, multicenter International Subarachnoid Aneurysm Trial demonstrated that there was a significant risk reduction after endovascular repair of ruptured aneurysms in comparison with surgical clipping and that there was long-term independence after the procedure [2]. Over time, the embolization of aneurysms in many institutions has become the frontline treatment option $[3,4]$. However, WNAs continued to present a greater challenge for coiling because of the risk of the coil mass protruding into the parent vessel as well as lower longterm occlusion rates [5]. Technological advancements have been introduced to assist in coiling of these lesions. Both balloon-assisted coiling (remodeling technique) and stent-assisted coiling are favored in the treatment of WNAs because they protect the parent vessel while coil- ing in either temporary or permanent fashion (stents with and without deployment) [6, 7]. However, balloon-assisted coiling temporarily obstructs flow, while the use of stents necessitates dual antiplatelet therapy, which carries increased procedural as well as long-term bleeding risks $[8,9]$. The Comaneci assist device is a controllable, nondetachable, and retrievable temporary bridging device that is used to assist in the coiling process [10-14].

In April 2019, the Comaneci embolization assist device (Rapid Medical, Yokneam, Israel) received US Food and Drug Administration classification Class II as a temporary coil embolization assist device. Although the device is new to the US market, it has been used with success previously in Europe and Israel [11-14]. As a bridging device, the Comaneci does not interfere with blood flow of the parent artery at the aneurysm neck base but can be expanded according to the aneurysm neck morphology 
Table 1. Patient and aneurysm anatomical characteristics, device used, time of exposure, and operative outcome

\begin{tabular}{|c|c|c|c|c|c|c|c|c|c|c|c|}
\hline Case & $\begin{array}{l}\text { Age, } \\
\text { years }\end{array}$ & Location & $\begin{array}{l}\text { Max } \\
\text { width, } \\
\text { mm }\end{array}$ & $\begin{array}{l}\text { Max } \\
\text { height, } \\
\text { mm }\end{array}$ & $\begin{array}{l}\text { Neck } \\
\text { size, } \\
\text { mm }\end{array}$ & $\begin{array}{l}\text { Dome-to- } \\
\text { neck ratio, } \\
\mathrm{mm}\end{array}$ & $\begin{array}{l}\text { Device } \\
\text { used }\end{array}$ & $\begin{array}{l}\text { Device } \\
\text { exposure } \\
\text { time, min }\end{array}$ & $\begin{array}{l}\text { Alternative } \\
\text { treatment }\end{array}$ & Outcome & Complications \\
\hline 1 & 49 & PCOM & 8.7 & 4.6 & 5.2 & 1.67 & 17 & 43 & & Neck remnant & \\
\hline 2 & 72 & Superior hypophyseal & 4 & 6.3 & 2.63 & 1.52 & Petit & 53 & & Complete occlusion & \\
\hline 3 & 55 & $\mathrm{ACOM}$ & 3 & 3.8 & 1.9 & 1.58 & 17 & 11 & & Complete occlusion & \\
\hline 4 & 60 & Basilar tip & 6.3 & 6 & 5.8 & 1.09 & 17 & 18 & & Near complete & \\
\hline 5 & 44 & ICA & 8.5 & 10 & 4.1 & 2.07 & Comaneci & 76 & & Complete occlusion & \\
\hline 6 & 73 & Choroidal & 5.2 & 3.5 & 3 & 1.73 & Comaneci & 15 & & Complete occlusion & \\
\hline 7 & 57 & PCOM & 7.7 & 4.2 & 4.6 & 1.67 & Comaneci & 8 & & Complete occlusion & \\
\hline 8 & 79 & PCOM & 6.3 & 3.7 & 4.2 & 1.5 & Comaneci & 13 & & Neck remnant & \\
\hline 9 & 58 & ACOM & 7.9 & 6.5 & 4.1 & 1.92 & 17 & 11 & & Neck remnant & \\
\hline 10 & 48 & ACOM & 4.8 & 5.5 & 4 & 1.2 & 17 & 15 & & Neck remnant & \\
\hline 11 & 57 & MCA & 5.6 & 4.4 & 3.3 & 1.7 & 17 & 29 & & Complete occlusion & \\
\hline 12 & 53 & MCA & 3.89 & 3 & 2.5 & 1.56 & 17 & 18 & & Complete occlusion & \\
\hline 13 & 55 & Vertebral & 9.9 & 8.65 & 6 & 1.65 & 17 & 24 & & Near complete & \\
\hline 14 & 68 & MCA & 6.7 & 11.8 & 5.26 & 1.27 & Petit and 17 & 26 & & Complete occlusion & \\
\hline 15 & 62 & MCA & 4.8 & 6.8 & 5.5 & 0.87 & 17 & 25 & Stent & Near complete & \\
\hline 16 & 67 & ACOM & 7 & 5.3 & 3.25 & 2.15 & 17 & 56 & & Complete occlusion & \\
\hline 17 & 47 & ACOM & 3.4 & 4 & 2 & 1.7 & 17 & 15 & & Complete occlusion & \\
\hline 18 & 77 & ACOM & 8 & 6.7 & 3.6 & 2.22 & 17 & 23 & & Complete occlusion & \\
\hline 19 & 63 & MCA & 6.9 & 6.7 & 6.5 & 1.06 & $2 \times 17$ & 25 & Stent & Residual filling & Device related \\
\hline 20 & 65 & ACOM & 8 & 8 & 4 & 2 & Petit & 9 & & Near complete & \\
\hline 21 & 58 & PCOM & 5 & 4 & 3 & 1.67 & Comaneci & 17 & & Complete occlusion & \\
\hline 22 & 81 & ACOM & 7.3 & 2.15 & 5.26 & 1.39 & 17 & 35 & & Complete occlusion & \\
\hline 23 & 42 & ACOM & 3.6 & 2.15 & 2.15 & 1.67 & 17 & 16 & & Complete occlusion & \\
\hline 24 & 76 & ACOM & 3.3 & 7.4 & 5.6 & 0.59 & 17 & 22 & & Complete occlusion & \\
\hline 25 & 74 & Basilar tip & 3 & 2 & 2.7 & 0.74 & 17 & 11 & & Complete occlusion & \\
\hline 26 & 77 & Basilar tip & 3.1 & 5.5 & 4.7 & 0.66 & 17 & 10 & & Near complete & \\
\hline
\end{tabular}

ACOM, anterior communicating artery; ICA, internal carotid artery; MCA, middle cerebral artery; PCOM, posterior communicating artery.

and vessel requirement [11]. Our objective was to provide further data regarding the use of the Comaneci embolization assist device after Food and Drug Administration approval in the USA.

\section{Methods}

We undertook a retrospective review of patients with WNAs treated for intracranial aneurysms via endovascular coiling with the assistance of the Comaneci (Fig. 1) at 4 institutions in the USA between July 2019 and May 2020. WNAs were defined as having an absolute neck width $>4 \mathrm{~mm}$ or a dome-to-neck ratio of $<2$. The only inclusion criterion was the use of the temporary bridging device. After the patients were identified, we reviewed all medical records and images taken during the procedure and periprocedural periods at the site hospitals. The primary end points of our retrospective review were (1) procedure success as measured by a lack of complications after the procedure, (2) the need to retreat the aneurysm with stent placement, and (3) thromboembolic events. Our secondary end point was the efficacy and effectiveness of Comaneci devices in a real-world setting.

\section{Results}

\section{Subject Demographics and Aneurysmal}

\section{Characteristics}

We identified 26 patients diagnosed with intracranial aneurysms who received Comaneci-assisted endovascular coil therapy (Table 1 ). The 18 women and 8 men included in the population were aged $44-81$ years, with a mean of 62.7 years.

Of the total sample size, 15 of the treated aneurysms had ruptured (presenting with subarachnoid hemorrhage) before the procedure, and 11 were unruptured. Ten subjects demonstrated aneurysms of the anterior communicating artery, 5 aneurysms were located on the middle cerebral artery, 4 aneurysms were on the posterior communicating artery, 3 were located at the basilar artery tip, and 1 each involved the anterior choroidal artery, the petrous internal carotid artery, the superior hypophyseal artery, and the vertebral artery. The mean aneurysm 

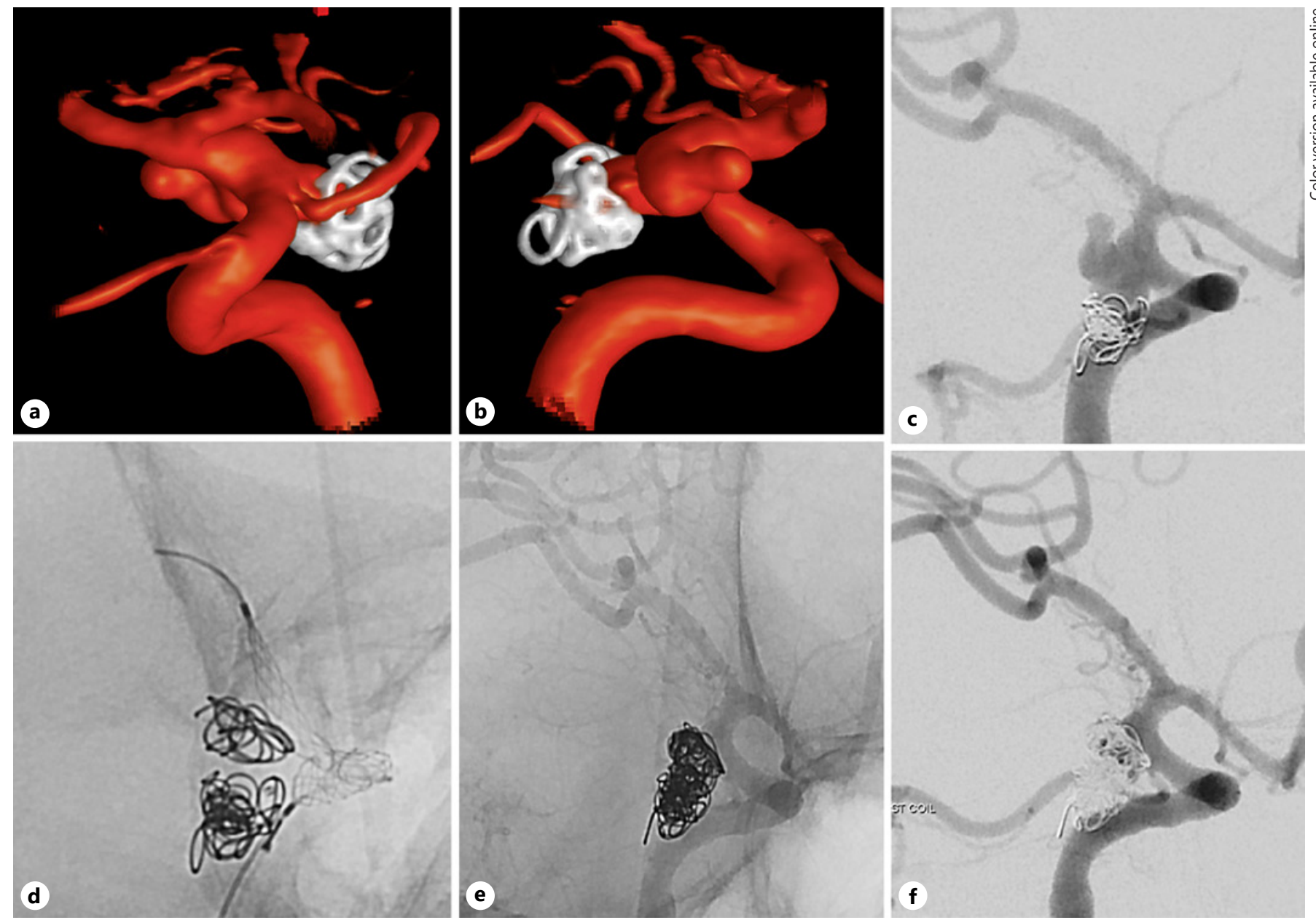

Fig. 2. Previously coiled, ruptured wide-neck, dysplastic PCOM aneurysm. a, b 3D reconstruction of the right ICA. c Anteroposterior oblique 2D DSA demonstrating the PCOM aneurysm with a daughter sac pointing superiorly and the compacted coil mass. A large PCOM is noted. d, e Unsubtracted image showing the inflated Comaneci after the first framing coil is deployed and after the last coil is deployed into the aneurysm. $\mathbf{f}$ DSA final result demonstrating near-complete occlusion of the aneurysm and patent PCOM artery. PCOM, posterior communicating artery; ICA, internal carotid artery.

height was $5.61 \mathrm{~mm}$ (range 2.0-11.8), and the mean maximal width was $5.80 \mathrm{~mm}$ (range 3.0-9.9), with mean neck size of $3.91 \mathrm{~mm}$ (range 1.9-6.5). The mean dome-to-neck ratio was $1.57 \mathrm{~mm}$ (range $0.59-3.39$ ).

\section{Use of Antiplatelets and Anticoagulants before the \\ Procedure}

The protocol for the use of antiplatelet and anticoagulant medications was fairly consistent. Aspirin and either clopidogrel or apixaban were provided for patients with unruptured aneurysms (in anticipation if treatment with the Comaneci device was unsuccessful and permanent stent placement was needed to facilitate coiling). Of the
11 patients with unruptured aneurysms, 8 patients were treated with dual antiplatelet therapy. Two received only aspirin monotherapy, and 1 patient did not receive any antiplatelet therapy. Any antiplatelet therapy was discontinued after the procedure after successful use of the Comaneci device. In unruptured cases, heparin was used at the start of microcatheterization in 10 of 11 patients. Among the 15 patients with ruptured aneurysms, 10 received no antiplatelet therapy and 5 received aspirin only. Heparin was administered after the deployment of the first coil in 14 of 15 cases. The 2 patients who required stent placement were given dual antiplatelet therapy in the form of aspirin and clopidogrel. 


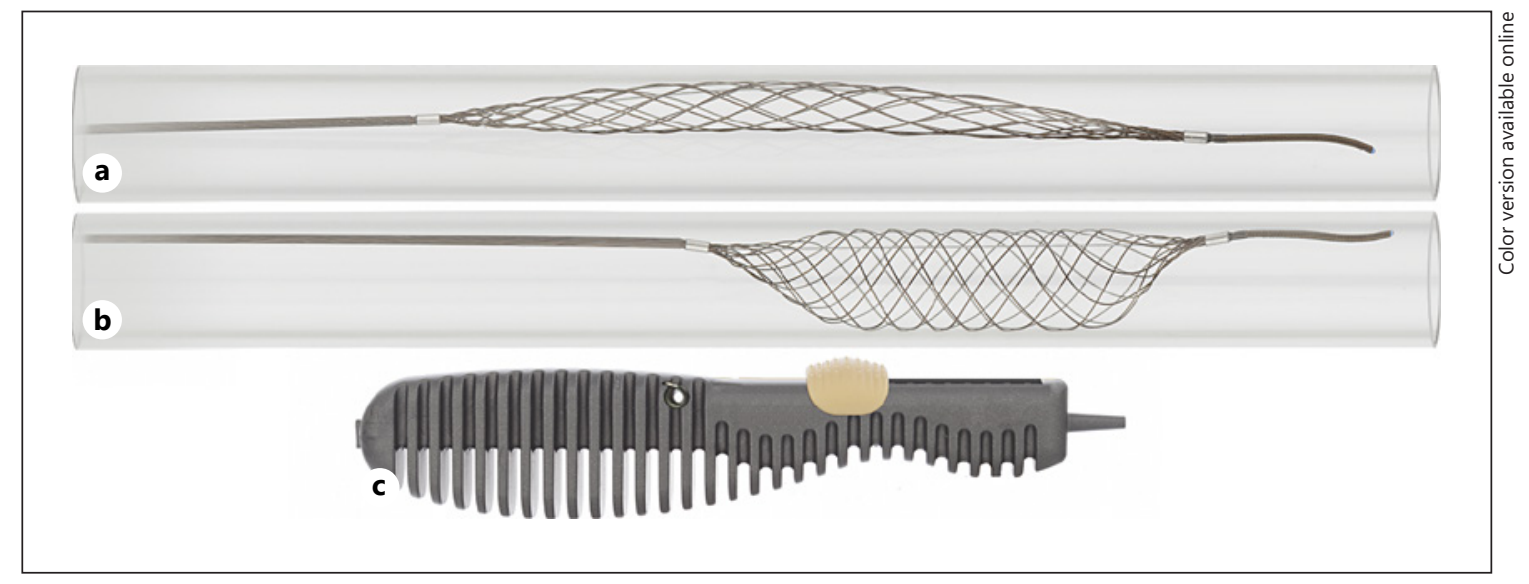

Fig. 3. Photographs of the Comaneci device. a The "deflated" Comaneci device after unsheathing the device from the microcatheter. b The Comaneci after "inflation" in a tube. c The handle of the Comaneci with its yellow adjustable slider on top, allowing for incremental control.

\section{Procedural Traits}

In 24 of 26 procedures, access to intracranial vessels was gained through the femoral artery, and in the other 2, access was via the radial artery. Twenty-eight total Comaneci devices were fully deployed: 2 patients required multiple and varying Comaneci devices. In the first case, 2 Comaneci 17 devices were simultaneously deployed. In the other, a Comaneci 17 and Comaneci Petit were used to achieve the same effect. In the remaining cases, seventeen Comaneci 17 devices, 5 standard Comaneci devices, and 2 Comaneci Petit devices were used. Notably, the Comaneci 17 device is compatible with a 0.017 -inch microcatheter and can be delivered through a dual-lumen balloon catheter.

In all of the patients, the physicians were able to deploy and navigate the device to successfully bridge the aneurysmal neck. The mean device exposure time ranged from 8 to $76 \mathrm{~min}$, with a mean of $24 \mathrm{~min}$. Two patients required stent placement. In 1 case, an Atlas stent (Stryker Neurovascular, Salt Lake City, UT, USA) was placed because of the morphology of the aneurysm. In another case, because of a device-related complication, 2 Atlas stents were required. In 2 separate cases, there was evidence of visible clot formation after removal of the devices at the end of the procedure; there were no clinical consequences.

Immediate procedural outcomes showed 16 of 26 cases where complete occlusion was achieved and 4 cases in which near-complete occlusion was achieved (Fig. 2). Five procedures resulted in neck remnant (Fig. 3; see online suppl. Video; for all online suppl. material, see www. karger.com/doi/10.1159/000514371). One displayed residual filling because of a device-related complication. The final angiographic images were reviewed to identify the aneurysm occlusion class - as determined by the Raymond-Roy Occlusion Classification. Of the 26 patients, 16 achieved Class I complete obliteration; 9 had nearcomplete obliteration or Class II residual neck, and 1 was Class IIIb, in which residual aneurysm with contrast along the aneurysm wall was noted.

\section{Intraprocedural Complications}

In 25 of 26 procedures, no complications, retreatments, or thromboembolic events occurred. One patient experienced a technical complication. In this instance, 2 bailout stents were required during the procedure. Two Comaneci 17 devices were placed in the superior and inferior division of the middle cerebral artery. Upon retrieval of the 2 devices, one of the coil loops was attached to the device and continued to pull through the aneurysm. Several attempts were made to recapture the device, but the removal resulted in the movement of the positioned coils out of the aneurysm and into the parent vessel. This event was treated with the placement of 2 Atlas stents with excellent result and no adverse outcome. The final angiographic image demonstrated normal antegrade flow in the affected arteries, but with residual aneurysm filling. On 3-month follow-up, complete occlusion had been achieved. No stroke events occurred.

\section{Discussion}

Our results illustrate the successful use of the novel Comaneci device as a temporary adaptable bridging device in the coil-assisted treatment of wide-neck aneu- 
rysms. In our series, the device was used in place of either balloon-assisted coiling or Y-stent-assisted coiling, without flow interruption during balloon inflation.

The WNAs included in our sample population are notoriously challenging and among the most difficult to treat with traditional endovascular techniques. Recognized risks include coil migration, protrusion, coil stretching, herniation, bleeding, thromboembolic events, and vasospasm [5]. As such, neurosurgical clipping is still a viable option for the treatment of WNAs $[13,15,16]$. The results of the Barrow Ruptured Aneurysm Trial showed no significant difference in long-term outcomes between clipping and coiling with respect to treatment of ruptured WNAs [5] and support microsurgical clipping as a viable management choice particularly in ruptured middle cerebral artery aneurysms [17]. This treatment paradigm has recently shifted with continued technological endovascular advancements, and it has become clear that endovascular therapy may be comparably safe and effective [16].

The medical literature suggests that this transition is in part due to the development of balloon-assisted coiling and stent-assisted coiling techniques. Both techniques aim to assist in the achievement of favorable occlusion rates while preventing coil herniation into the parent vessel. Balloon remodeling involves the temporary placement of an inflated balloon across the neck of an aneurysm. In the presence of a balloon, more packing density as well as more favorable coiling at the aneurysm neck is possible. Stent-assisted coiling is the placement of a selfexpanding stent in an effort to support the coil mass across an aneurysmal wide neck, similarly, to facilitate coiling and promote more durable occlusion $[13,15,16]$. Although both methods are associated with good clinical outcomes and low morbidity rates, balloon remodeling may be preferable in some clinical situations because antiplatelet therapy is not routinely necessary [16]. Antiplatelet therapy, in conjunction with heparin anticoagulation, lowers the risk of thromboembolic events; however, the use of both or either drug regimens may put patients at higher risk for hemorrhagic events [18].

The earliest account of the Comaneci device was an animal study by Gupta et al. [10] that examined aneurysm coiling facilitated by the Comaneci device when compared with a compliant HyperGlide balloon (Medtronic, Minneapolis, MN, USA). The authors found similar rates of aneurysm obliteration as well as endothelial damage in both subacute and chronic phases, suggesting a favorable safety profile for the Comaneci device. Lawson et al. [11] then presented the first clinical case report of its successful use in the treatment of cerebral aneurysms. They re- ported one thromboembolic complication, the precise cause of which was not clear. Multiple reports followed showing promising results with the Comaneci device in the treatment of wide-necked cerebral aneurysms, both unruptured [12] and ruptured [13, 14, 19]. Fisher et al. [12] reported one thromboembolic event in their series of 21 cases, while Sirakov et al. [13] reported 1 case of 29 in which there was severe intraoperative vasospasm and coil protrusion after retraction of the device.

The basic premise of balloon-assisted coiling can be seen in the Comaneci device-assisted coiling strategy; the functionality is similar, but there is no obstruction to the antegrade flow of the parent vessel. This advantage may be significant, as allowing blood flow to continue uninterrupted lowers the chance of thromboembolic events. It also significantly lowers the risk of vessel rupture, which is a known catastrophic complication of balloon-assisted coiling. A potential limitation of the Comaneci coil assist technique is the inability to obstruct the parent vessel in the event of intraprocedural rupture $[13,16]$. Among the various complications associated with endovascular coil embolization, perhaps the most formidable is that of intraprocedural aneurysm rupture. For this reason, some physicians believe balloon remodeling is desirable because the balloon may be inflated, giving physicians more time to control the rupture. Intraprocedural aneurysm rupture while using the Comaneci device would require physicians to control the situation in the same manner as if no balloon was used [20]. Thus, in cases that were high risk for intraprocedural rupture, we delivered the Comaneci 17 device through a Scepter dual-lumen balloon catheter (Microvention, Tustin, CA, USA) in order to have a balloon in the parent vessel proximal to the aneurysm in case a rupture occurred.

The complication of coil entanglement with the struts of the device is rare but possible as seen in one of our cases. The key is to maintain visibility at the neck of the aneurysm, using a working angle that shows the demarcation between the device and the coils. In cases where visualization is not possible, we recommend resheathing or collapsing the device before detachment of coils to ensure no entanglement just as you would deflate a balloon before delivering a coil.

The limitations of this study include its retrospective nature, small number of patients, and lack of long-term follow-up. Furthermore, the absence of a control group treated with either stent-assisted or balloon-assisted coiling techniques limits our ability to extrapolate the effectiveness of Comaneci-assisted coiling in comparison with these current more standard methods of endovascular treatment for WNAs. 


\section{Conclusions}

Overall, our initial and admittedly limited experience with the Comaneci device demonstrates potential advantages over traditional endovascular treatment strategies. It appears to be a safe and effective alternative to balloonassisted and stent-assisted coiling techniques. More research and a larger experience are needed to fully understand its role in the endovascular management of widenecked aneurysms.

\section{Statement of Ethics}

On May 26, 2020, Western Institutional Review Board approved a request for a waiver of authorization for use and disclosure of protected health information for this research. This exemption is believed to be exempt under 45 CRF $\$ 46.104(\mathrm{~d})(4)$ because this research involved retrospective review of adult patient charts who received treatment with the Comaneci embolization assist device. The use of the device during procedure was made outside of this research, and data were collected and reported in such a way that human subjects cannot be ascertained directly or through identifiers linked to the subjects. This exemption does apply to multiple sites except for institutions that fall under the jurisdiction of a local IRB; in these cases, further arrangements were made.

\section{Conflict of Interest Statement}

Erez Nossek is a consultant for Rapid Medical. Rishi Gupta is the primary investigator of the TIGER Study. Muhammad Asif Taqi is a consultant for Rapid Medical and a site investigator of the TIGER Study. Philipp Taussky is a consultant for Medtronic, Stryker, and Cerenovus. Howard A. Riina is a consultant for Medtronic.

\section{Funding Sources}

The authors of this manuscript have received no specific funding for this work.

\section{Author Contributions}

Substantial contribution to the conception or design of the work: M.T., E.N., E.R., A.V., M.S., R.G., P.T., H.R., and PN. Acquisition, analysis, or interpretation of the data for the work: M.T., E.R., A.V., R.G., P.T., and E.N. Drafting the work or revising it critically for important intellectual content: M.T., E.R., A.V., J.H., and E.N. Agreement to be accountable for all aspects of the work in ensuring that questions related to the accuracy or integrity of any part of the work are appropriately investigated and resolved: M.T., E.R., A.V., M.S., R.G., J.H., P.T., H.R., P.N., and E.N.

\section{References}

1 Lin N, Cahill KS, Frerichs KU, Friedlander $\mathrm{RM}$, Claus EB. Treatment of ruptured and unruptured cerebral aneurysms in the USA: a paradigm shift. J Neurointerv Surg. 2018 Jul; 10(Suppl 1):i69-76.

2 Molyneux AJ, Kerr RS, Yu LM, Clarke M, Sneade M, Yarnold JA, et al. International subarachnoid aneurysm trial (ISAT) of neurosurgical clipping versus endovascular coiling in 2143 patients with ruptured intracranial aneurysms: a randomised comparison of effects on survival, dependency, seizures, rebleeding, subgroups, and aneurysm occlusion. Lancet. 2005 Sep 3-9;366(9488):809-17.

3 Brilstra EH, Rinkel GJ, van der Graaf Y, van Rooij WJ, Algra A. Treatment of intracranial aneurysms by embolization with coils: a systematic review. Stroke. $1999 \mathrm{Feb} ; 30(2): 470-6$.

4 Qureshi AI, Vazquez G, Tariq N, Suri MF, Lakshminarayan K, Lanzino G. Impact of International Subarachnoid Aneurysm Trial results on treatment of ruptured intracranial aneurysms in the United States. Clinical article. J Neurosurg. 2011 Mar;114(3):834-41.

5 Mascitelli JR, Lawton MT, Hendricks BK, Nakaji P, Zabramski JM, Spetzler RF. Analysis of wide-neck aneurysms in the barrow ruptured aneurysm trial. Neurosurgery. 2019 Nov 1; 85(5):622-31.
6 Moret J, Cognard C, Weill A, Castaings L, Rey A. [Reconstruction technic in the treatment of wide-neck intracranial aneurysms. Longterm angiographic and clinical results. Apropos of 56 cases]. J Neuroradiol. 1997 Jun; 24(1):30-44.

7 Brinjikji W, Cloft HJ, Kallmes DF. Difficult aneurysms for endovascular treatment: overwide or undertall? AJNR Am J Neuroradiol. 2009 Sep;30(8):1513-7.

8 Sluzewski M, van Rooij WJ, Beute GN, Nijssen PC. Balloon-assisted coil embolization of intracranial aneurysms: incidence, complications, and angiography results. J Neurosurg. 2006 Sep;105(3):396-9.

9 Tumialan LM, Zhang YJ, Cawley CM, Dion JE, Tong FC, Barrow DL. Intracranial hemorrhage associated with stent-assisted coil embolization of cerebral aneurysms: a cautionary report. J Neurosurg. 2008 Jun;108(6): 1122-9.

10 Gupta R, Kolodgie FD, Virmani R, Eckhouse R. Comaneci neck bridging device for the treatment of cerebral aneurysms. J Neurointerv Surg. 2016 Feb;8(2):181-5.
11 Lawson AL, Chandran A, Puthuran M, Goddard T, Nahser H, Patankar T. Initial experience of coiling cerebral aneurysms using the new Comaneci device. J Neurointerv Surg. 2016 Aug;8(8):e32.

12 Fischer S, Weber A, Carolus A, Drescher F, Götz F, Weber W. Coiling of wide-necked carotid artery aneurysms assisted by a temporary bridging device (Comaneci): preliminary experience. J Neurointerv Surg. 2017 Nov; 9(11):1039-97.

13 Sirakov S, Sirakov A, Hristov H, Minkin K, Penkov M, Karakostov V. Early experience with a temporary bridging device (Comaneci) in the endovascular treatment of ruptured wide neck aneurysms. J Neurointerv Surg. 2018 Oct;10(10):978-82.

14 Sirakov SS, Sirakov A, Hristov H, Raychev R. Coiling of ruptured, wide-necked basilar tip aneurysm using double Comaneci technique. BMJ Case Rep. 2018 May 18;2018:2018.

15 Cottier JP, Pasco A, Gallas S, Gabrillargues J, Cognard C, Drouineau J, et al. Utility of balloon-assisted Guglielmi detachable coiling in the treatment of 49 cerebral aneurysms: a retrospective, multicenter study. AJNR Am J Neuroradiol. 2001 Feb;22(2):345-51. 
16 Chalouhi N, Starke RM, Koltz MT, Jabbour PM, Tjoumakaris SI, Dumont AS, et al. Stentassisted coiling versus balloon remodeling of wide-neck aneurysms: comparison of angiographic outcomes. AJNR Am J Neuroradiol. 2013 Oct;34(10):1987-92.

17 Mooney MA, Simon ED, Brigeman S, Nakaji P, Zabramski JM, Lawton MT, et al. Longterm results of middle cerebral artery aneurysm clipping in the barrow ruptured aneu- rysm trial. J Neurosurg. 2018 Apr 27;130(3): 895-901.

18 Yamada NK, Cross DT 3rd, Pilgram TK, Moran CJ, Derdeyn CP, Dacey RG Jr. Effect of antiplatelet therapy on thromboembolic complications of elective coil embolization of cerebral aneurysms. AJNR Am J Neuroradiol. 2007 Oct;28(9):1778-82.

19 Sirakov SS, Panayotova AP, Sirakov AS, Hristov H, Minkin K, Raychev R. Fenestration of the basilar artery associated with aneurysm treated by the support of a temporary bridging device-comaneci: a case report. World Neurosurg. 2018 Nov;119:306-10.

20 Santillan A, Gobin YP, Greenberg ED, Leng LZ, Riina HA, Stieg PE, et al. Intraprocedural aneurysmal rupture during coil embolization of brain aneurysms: role of balloon-assisted coiling. AJNR Am J Neuroradiol. 2012 Nov; 33(10):2017-21. 